\title{
Policy making for smart cities: innovation and social inclusive economic growth for sustainability
}

\section{Introduction}

This paper aims to query the scientific debate related to a new generation of policy-aware smart cities research geared towards innovation and socially inclusive economic growth for sustainability. It summarizes the rationale behind the relevant JSTPM Special Issue and its overall objective to serve as a reference for policymakers, educators, practitioners, government and think-tank officers interested in the emerging topics in smart cities research. This paper examines the state-of-the-art of smart cities research and provides an overview of papers included in the special issue. The approach is related to meta-desktop research aiming to reveal the key contributions and open research issues related to policymaking for smart cities research. This paper makes a case for opening the smart cities concept to a new generation of sophisticated ICT-enabled solutions. It is argued that more structured and output-oriented dialogue among a variety of stakeholders is needed, and that the debate needs to focus on new sustainable, global and socially aware polices for research on smart cities, smart regions and smart clusters. To this end, greater attention needs to be paid to emerging technologies, such as the internet of things, cognitive computing, advanced analytics and business intelligence, $5 \mathrm{G}$ networks, anticipatory and context-aware computing and advanced distributed data warehouse platforms. This editorial introduces the debate that unfolds in the Special Issue. It also highlights how this debate could be enriched by means of international collaboration and scientific dialogue. By highlighting the variety of research related to smart cities' policymaking, this paper offers a typology of the services and applications that target data-driven policymaking at the micro, mezzo and macro levels. This paper argues that sustainability and innovation are two integral aspects of the same social challenge. The integration of sophisticated technological platforms and advanced policies requires a new managerial paradigm at all levels of decision-making across and beyond continents and local boundaries. This Special Issue is one of the first attempts worldwide to discuss the socially aware policy-making process as an inevitable part of smart cities' research.

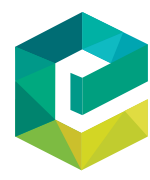

Journal of Science and Technology Policy Management Vol. 9 No. 2, 2018 pp. 126-133

(C) Emerald Publishing Limited 2053-4620

DOI 10.1108/JSTPM-07-2018-079

\section{The research landscape of smart cities research: the policy-wide spectrum of ICT-enabled innovation}

The strategic objective of improving the quality of services in modern cities and urban areas and their transformation to evolving dynamic organisations with digital reference layers enabling unique service experiences is a key challenge of our times. In fact, smart cities provide a context for a multidisciplinary discussion related to the value-added proposition of several leading-edge technologies, including immersive technologies, virtual and augmented reality (Lytras et al., 2016), wearable technologies, cloud computing, data science, big-data insights, social networks (Lytras and Mathkour, 2017), Web applications and internet technologies (Lytras et al., 2017; Wu et al., 2018). 
According to the Digital Agenda for Europe, the smart cities concept means smarter urban transport networks, upgraded water supply and waste-disposal facilities, along with more efficient ways to light and heat buildings. In addition, it encompasses a more interactive and responsive city administration, safer public spaces and meeting the needs of an ageing population (Visvizi et al., 2017). It is a new paradigm, with the integration of internet technology in the urban context. The focus of the Special Issue is to analyse in depth the revolutionary role of internet technology for the integration and interconnection of citizens, businesses and government. This is a key requirement for the exploitation of some for smart cities of the latest technology.

A number of key issues are in the focus of this Special Issue, including technology enablers, smart cities strategies and socially aware policymaking (Figure 1).

The future of cities is smart. Numerous commercial partnerships, as well as various research organisations worldwide, are currently in a race to create smart cities applications. Advanced internet technologies are providing smart applications for almost every domain of human activity in the urban context and for smart government. Smart cities internet technology is the focus of this Special Issue, aiming to foster a scientific debate for the new era of urban computing. Next, we summarise the key contributions of this edition.

\section{Overview of selected papers}

Anna Visvizi and Miltadis Lytras, in their position research paper entitled Rescaling and refocusing smart cities research: from mega cities to smart villages query the smart cities debate. By reference to the mega cities research, the authors argue that smart city remains an overly normatively laden concept frequently discussed in separation of broader socio-political and economic contexts in which it is embedded. By focusing on what is termed normative bias of smart cities research, the paper introduces the nested clusters model. By advocating the inclusion of policymaking and strategy considerations in the smart cities debate, a case is made for a holistic, scalable and human-centred smart cities agenda focused, on the one hand, on individuals and citizens inhabiting smart cities, and on the other hand, on interdependencies that unfold between a given smart city and the context in which it is embedded.

By highlighting the relatively under-represented in the literature connection between the normative and the empirical in the smart cities research, this paper encourages a more structured debate between academia and policymakers focused on sustainable development of cities/urban areas. By so doing, this paper also advocates policies and strategies conducive to strengthening individuals'/citizens' ability to benefit from and contribute to the

\begin{tabular}{|c|c|c|c|c|c|}
\hline 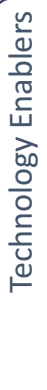 & $\begin{array}{l}\text { Data Management } \\
\text { Web Services for Smart } \\
\text { Cities } \\
\text { Social Networks } \\
\text { Sensoring, Cloud, GIS } \\
\text { applications } \\
\text { Internet of Things for } \\
\text { Urban Computing } \\
\text { Wearable and Immersive } \\
\text { Technologies } \\
\text { Advanced Data Mining }\end{array}$ & 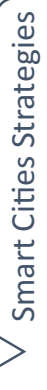 & $\begin{array}{l}\text { Urban Innovation } \\
\text { Research into Sustainable } \\
\text { Innovations } \\
\text { Case Studies of Smart } \\
\text { Cities Research } \\
\text { Smart Cities Strategies } \\
\text { and Integration } \\
\text { Caring Communities and } \\
\text { Innovations } \\
\text { Social Innovation } \\
\text { Business Models for } \\
\text { Smart Cities }\end{array}$ & 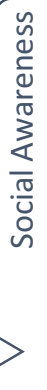 & $\begin{array}{l}\text { Social Wellbeing, } \\
\text { Smart Communities; } \\
\text { Open Access to } \\
\text { Knowledge } \\
\text { Open Governance, Open } \\
\text { Data, Linked Data for } \\
\text { Smart Cities } \\
\text { Smart Cities, Inequalities } \\
\text { and Inequities } \\
\text { Security and Privacy } \\
\text { Issues in Smart Urban- } \\
\text { Services Provision }\end{array}$ \\
\hline
\end{tabular}

Source: The authors

Figure 1.Open issues for smart cities research: technology enablers, smart cities strategies and social awareness 
JSTPM

9,2

128 smart cities development, thereby making them sustainable. Overall, this paper makes a case for a pragmatic and demand-driven smart cities research, i.e. based on frequently very basic needs of individuals and citizens inhabiting urban and rural areas. It also highlights the role of basic infrastructure as the key enabler/inhibitor of ICT-enhanced services. The nested clusters model, which Visvizi and Lytras introduce, suggests that an intimate connection exists between individuals' well-being, their active civic engagement and smart cities' sustainability. In this view, this paper promotes a smart cities' agenda based on functional connections between the key clusters forming the urban space, where knowledge creation and knowledge-based strategic thinking serve as the levers of sustainability.

Margarita Angelidou, Artemis Psaltoglou, Nicos Komninos, Christina Kakderi, Panagiotis Tsarchopoulos and Anastasia Panori, in their research work entitled Enhancing sustainable urban development through smart cities applications, investigate the potential contribution of smart cities' approaches and tools to sustainable urban development in the environment domain. Recent research has highlighted the need to explore the relation of smart and sustainable cities more systematically, focusing on practical applications that could enable a deeper understanding of the included domains, typologies and design concepts, and this paper aims to address this research gap. At the same time, it tries to identify whether these applications could contribute to the "zero vision" strategy, an extremely ambitious challenge within the field of smart cities.

The findings suggest that the smart and sustainable city landscape is extremely fragmented both on the policy and technical levels. There is a host of unexplored opportunities toward smart, sustainable development, many of which are still unknown. Similar findings are reached for all categories of environmental challenges in cities. The research limitations pertain to the analysis of a relatively small number of applications. The results can be used to inform policymaking towards becoming more proactive and impactful policy, both locally and globally. Smart cities application market niches are also identified, which should be of special interest to developers, user communities and digital entrepreneurs. The added value of this paper is twofold. At the theoretical level, it offers a conceptual bridge between the smart and sustainable cities debate. At the practical level, it identifies under-researched and under-exploited fields of smart cities applications that could be opportunities to attain the "zero vision" objective.

Miguel Torres-Ruiz, Marco Moreno-Ibarra, Wadee Alhalabi, Rolando Quintero and Giovanni Guzmán, in Towards a microscopic model for analysing the pedestrian mobility in an urban infrastructure, introduce a microscopic model that describes pedestrian behaviour in two-dimensional space. It is based on multi-agent systems and cellular automata theory. The concept of layered intelligent terrain from the video-game industry is reused, as well as concepts such as tracing, evasion and rejection effects related to pedestrian interactive behaviour. In a simulation scenario, an agent represents a pedestrian with homogeneous physical characteristics, such as walking speed and height. The agents are moved through a discrete space formed by a lattice of hexagonal cells where each one can contain up to one agent at the same time. The model was validated by using a test composed of 17 real datasets of pedestrian unidirectional flow. Each dataset has been extracted from laboratorycontrolled scenarios carried out with up to 400 people walking through a corridor whose configuration changed in the form of the amplitude of its entrance doors and the amplitude of its exit doors from one experiment to another. Moreover, each dataset contained different groups of coordinates that compose pedestrian trajectories. The scenarios were replicated and simulated using the proposed model, obtaining 17 simulated datasets.

In addition, a measurement methodology based on Voronoi diagrams was used to compute the velocity, density and specific flow of the pedestrians to build a time-series graphic and a set of heat maps for each of the real and simulated datasets. The social impact 
is directly related to the behaviour analysis of pedestrians to know tendencies, trajectories and other features that aid the improvement of public facilities. The general methodology is the main value of this work. Many approaches were used, designed and implemented for analysing the pedestrians' behaviour. In addition, all the methods were implemented as a plug-in for Quantum GIS. The results could be used to generate policies oriented towards developing more conscious public infrastructure development.

Chatterjee Sheshadri and Kar Arpan, in Effects of the successful adoption of informationtechnology-enabled services in proposed smart cities of India from a user-experience perspective, investigate how IT-enabled services could transform the lives of residents, both socially and technologically, the extent the prospective citizens will be engaged to use the modern services and the threat of privacy and security issues affecting the overall performance of the proposed smart cities of India. It also examines how gaining the trust of citizens can help in the successful adoption of IT services. The research reported in this paper is the outcome of an indepth study on proposed Indian smart cities, especially in IT adoption and from a user's perspective. There is very little research carried out on the proposed Indian smart cities from an IT adoption standpoint and how that could improve the lifestyle of the residents.

Harish Kumar, Manoj Singh, M.P. Gupta and Jitendra Madaan, in Smart neighbourhood: a TISM approach to reduce urban polarization for the sustainable development of smart cities, identify the key factors to design efficient, healthy and economically viable neighbourhoods surrounding smart cities to reduce urban polarization in sustainable urban development. A two-stage methodology is followed. First, the key factors for the neighbourhood are identified from literature reviews. The selected factors are validated by a sample $t$-test. Second, total interpretive structural modelling (TISM) is used to interpret the complexity of the relationships between various factors. Further, MICMAC analysis is used to find the driving factors for neighbourhood design. This paper will aid policymakers, city planners and government officials to design a sustainable smart cities model in which a smart neighbourhood would also be the potential solution to decrease pressure on a city's critical infrastructure, especially in developing countries. A smart city could be considered the centre point of smart initiatives to develop a place and should continue beyond the city's boundaries to enhance the facilities, services, resources utilisation and working environment in neighbourhood areas also.

Isabel Novo-Corti, Jose Picatoste, Laura Ortiz-Pérez and Miguel Ruesga Benito Santos, in their Smart cities for wellbeing: youth employment and their skills on computers, elaborate on the connection of smart cities and well-being. Smart cities can be understood as an inclusive space for everyone to achieve their best options within the framework of sustainable development, where institutions boost the level of information and technology environments to help citizens' achieve their highest individual and social well-being, with the aim of improving their lives. The group between 15 and 24 years old was strongly affected by the recent global economic crisis. In this paper, youth employment in relation to the new challenges of smart cities is analysed in the EU, with the aim of assessing the influence of ICT skills on youth employability. The main, original value of this work is to relate the computer skills and employment rates for youth in the framework of the EU.

Aqeel Farooq, Wadee Alhalabi and Sara Alahmadi, in Traffic systems in smart cities using LabVIEW, designed and applied LabVIEW to traffic maintenance and flow by introducing improvements to a smart city. The objective is to introduce automated Human Machine Interface - a computer-based graphical user interface for traffic flow, measurement and detecting faults at the extremes (pole). This includes considerable measures of the flow of traffic, violation detection in the signal, fault measurement in the traffic pole, locking down cars for emergencies and measuring parameters inside cars (Figure 2). 


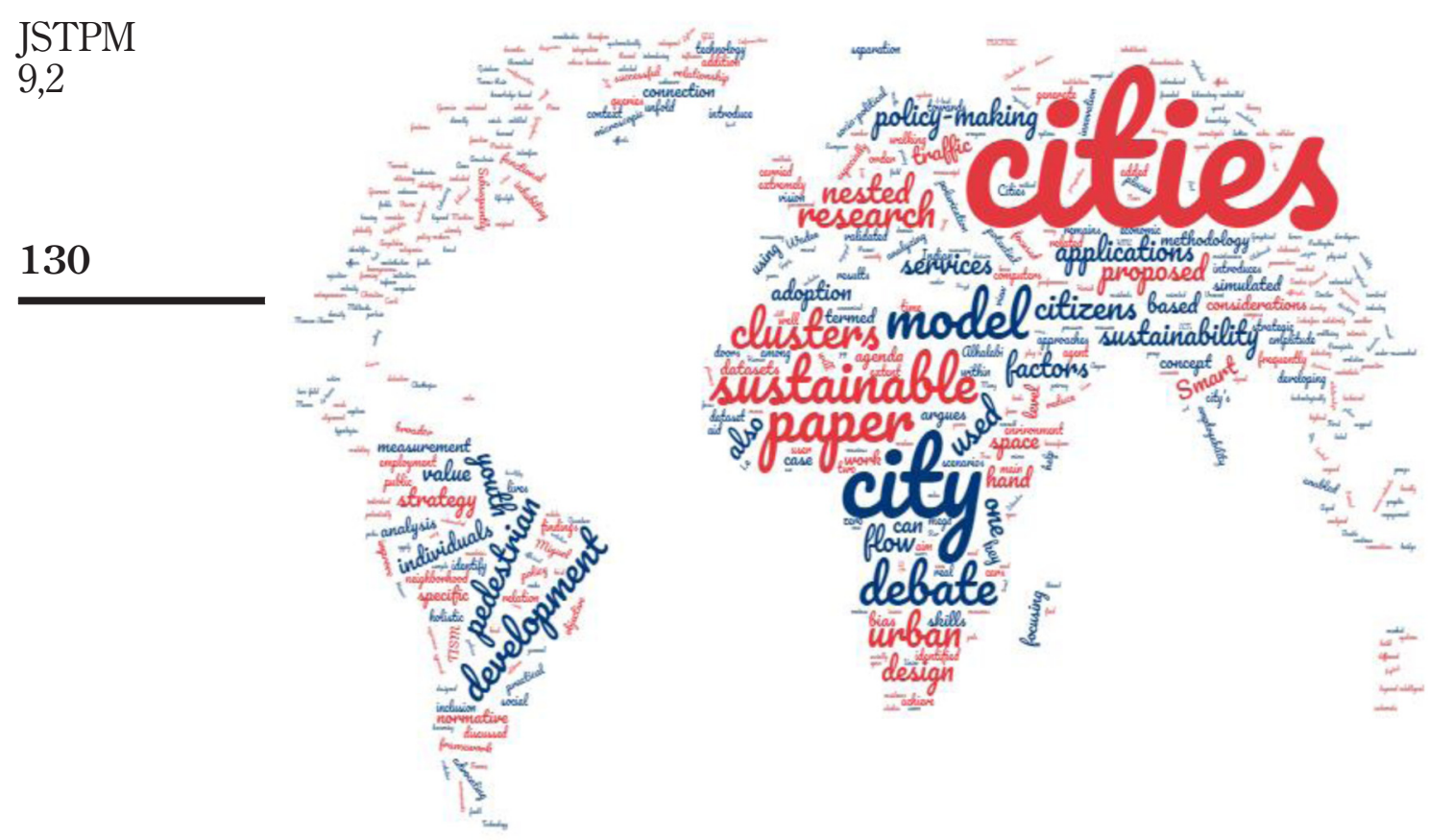

Figure 2.

Visualization of topics and issues discussed in this special issue

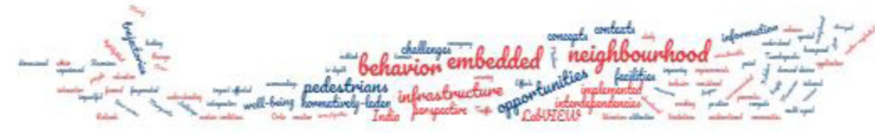

\section{The research landscape of smart cities research: the policy-wide spectrum of ICT-enabled innovation}

The debate in this Special Issue was focused mostly on the micro level of smart cities research. This serves as an inevitable reference layer for all the strategic consultation and policy-driven decisions related to sustainable smart cities research. This Special Issue is in fact the second of a planned series of special issues. Our current initiatives integrate five complementary areas of focus:

(1) smart-village research at the micro level;

(2) smart cities applications and urban computing at the middle level;

(3) smart-cluster and innovation-network research at the macro level;

(4) data-driven decisions for policymaking, governance, and strategy; and

(5) one belt, one road and silk road research, Gulf Cooperation Council research, bold innovation partnerships between Europe and Asia, and transatlantic research excellence.

Some of the key concerns at the micro level include:

- codification and standardisation of smart data for citizens;

- annotation of smart services in the smart cities context for dynamic composition and personalisation; 
- ease of context-aware algorithms for advances in the provision of services;

- establishment of advanced networking capabilities, including mobile, smart, sensor, for smart cities and $5 \mathrm{G}$ networks;

- interoperability issues between diverse distributed smart cities services;

- integration to single-point-of-access, one-stop-shop smart cities services;

- awareness and training of citizens in smart cities skills and competence;

- geospatial- and location-aware smart cities services; and

- integrated methodologies for smart cities urban applications in the local context.

In the next section, we provide a guest editors' point of view on the future of research in the micro, mid and macro levels of smart cities research.

\section{Open future technological and policymaking-oriented research issues}

In this part, we present some areas of future research. A more detailed discussion is planned for our forthcoming Special Issue of JSTPM, titled From smart cities to smart clusters: rethinking regional collaboration and development.

\subsection{Micro level}

At the micro level of analysis, technology utilisation contributes interesting applications. A key requirement is advanced citizen profiling, taking into consideration structured and unstructured knowledge related to individuals and citizens. Towards this direction, research issues related to the semantic annotation of content and services is critical, as well as advanced distributed data warehouse implementations. Furthermore, this unified approach to data repository management requires novel, creative approaches to measurable, visual key performance indicators of smart cities efficiency. There is also a critical inquiry for one-stop-shop access to services for using smart cities infrastructure. In the financial micro context, the exploitation of blockchain and epayment technologies will promote a new era for the management of financial streams within the micro context. On the demand side of the micro level, artificial intelligence will boost significant, ubiquitous recommender systems capable of processing big data in real time and for any purpose, which justifies relevant policy orientations.

\subsection{Middle level}

At the middle level, one of the most significant research challenges is to design adaptive, context-aware anticipatory computing crawlers and services that will add additional insight to data profiles. Service annotators will exploit the capacities of data crawlers for personalized matching of the tri-part data - services - decision-making process. In the analytics domain, the main emphasis will be on advanced business-intelligence methods, including classification, clustering, sentiment analysis, opinion mining and emotions. The provision of numerous smart services through the cloud context also will increase the flexibility of setting up and managing distributed innovation services in cities and regions. The integration of transparent financial engineering will also lead to sophisticated context-aware infrastructure.

\subsection{Macro level}

The data management strategies in this level deal with uncertainty and risk. They exploit numerous interoperable intelligent agents across local and regional boundaries that extract in real time data shared between different IT infrastructure. Advanced analytical capabilities, both descriptive and predictive, maintain and monitor different qualitative 
JSTPM

9,2

\section{2}

Table I.

Technological research issues and application domain developmental indexes related to innovation, socially inclusive economic growth and sustainability. Matching, ranking and advanced similarity algorithms are used in focused analytics combining behaviour, business, politics and various other domains of human activity. At a strategic level, infrastructure promoting policy-aware objectives and strategies are offered in the cloud for universal use. Blockchain technology is also used to manage interoperable marketplaces for everything. Innovation networks and clusters of innovation span and extend beyond time and space limitations (Table I).

Beyond the technological challenges for the new generation of smart cities research, it is quite interesting to summarize at a glance the main policy-making research issues. In Table II, we provide a brief introduction to this debate. In the next Special Issue planned in JSTPM, we aim to discuss them more thoroughly.

\section{Conclusions}

The integration of smart cities research into modern theories of sustainable economic development and applied-technology-enabled innovative projects requires a holistic approach. This Special Issue in fact serves as a starting point in an ongoing debate about the required convergence of technological policymaking and economic development across and beyond cultures and local boundaries. The ultimate vision is a collective, distributed humanity with bold responses to crucial social and economic development problems that arise. Within this context, the happiness of people, the quality of their lives, justice and respect of human rights must be integral propositions of any smart approach. In the same

\begin{tabular}{|c|c|c|c|}
\hline Technology sophistication & Micro & $\begin{array}{l}\text { Smart context } \\
\text { Middle }\end{array}$ & Macro \\
\hline Data aggregation & $\begin{array}{l}\text { Citizen profiling } \\
\text { Semantic annotation } \\
\text { Integrated-data } \\
\text { warehouses }\end{array}$ & $\begin{array}{l}\text { Data crawlers } \\
\text { Service annotators }\end{array}$ & $\begin{array}{l}\text { Interoperable intelligent } \\
\text { Agents }\end{array}$ \\
\hline Analytics & $\begin{array}{l}\text { Visual KPIs } \\
\text { Link analysis }\end{array}$ & $\begin{array}{l}\text { Business intelligence } \\
\text { Behaviour mining }\end{array}$ & $\begin{array}{l}\text { Development indexes } \\
\text { Matching algorithms }\end{array}$ \\
\hline Cloud & One-stop-shop access & Smart cloud services & Infrastructure as a service \\
\hline Blockchain & Financial streams & $\begin{array}{l}\text { Transparent financial } \\
\text { engineering }\end{array}$ & $\begin{array}{l}\text { Interoperable } \\
\text { marketplaces }\end{array}$ \\
\hline Artificial Intelligence & $\begin{array}{l}\text { Recommender } \\
\text { systems }\end{array}$ & $\begin{array}{l}\text { Context-aware } \\
\text { infrastructure }\end{array}$ & $\begin{array}{l}\text { Innovation networks } \\
\text { Clusters of innovation }\end{array}$ \\
\hline
\end{tabular}

\begin{tabular}{|c|c|c|c|}
\hline $\begin{array}{l}\text { Policy orientation and } \\
\text { strategy }\end{array}$ & Micro & $\begin{array}{l}\text { Smart context } \\
\text { Middle }\end{array}$ & Macro \\
\hline Innovation & Smart-village research & $\begin{array}{l}\text { Domain-specific (e.g., } \\
\text { smart tourism) } \\
\text { E-marketplace of } \\
\text { capabilities and skills } \\
\text { Smart regions }\end{array}$ & $\begin{array}{l}\text { Innovation networks } \\
\text { Management of } \\
\text { distributed high-tech } \\
\text { clusters }\end{array}$ \\
\hline $\begin{array}{l}\text { Socially Inclusive } \\
\text { Economic Growth } \\
\text { Sustainability }\end{array}$ & $\begin{array}{l}\text { Business modelling } \\
\text { Social networking } \\
\text { Resource-based } \\
\text { optimisation }\end{array}$ & $\begin{array}{l}\text { Startup ecosystems } \\
\text { Social businesses } \\
\text { Smart cities research }\end{array}$ & $\begin{array}{l}\text { Distributed clusters of } \\
\text { economic growth } \\
\text { Smart regions } \\
\text { Smart clusters }\end{array}$ \\
\hline
\end{tabular}


direction, the key challenge for creative leadership, innovative strategies and human-centric policymaking is the conclusion of this special edition. We will meet again in the future with an updated discussion on the subject matter of this Special Issue.
Policy making for smart cities

Anna Visvizi

School of Business, Deree College - The American College of Greece, Athens, Greece and Effat College of Business, Effat University, Jeddah, Saudi Arabia Miltiadis D. Lytras

Department of Business, Deree College - The American College of Greece, Athens, Greece and Effat College of Engineering, Effat University, Jeddah, Saudi Arabia

Ernesto Damiani

Khalifa University of Science Technology, Abu Dhabhi, United Arab Emirates, and

Hassan Mathkour

College of Computer and Information Science, King Saud University, Riyadh, Saudi Arabia

\section{References}

Lytras, M.D. and Mathkour, H. (2017), "Advances in research in social networking for open and distributed learning", The International Review of Research in Open and Distributed Learning, Vol. 18 No. 1, pp. 1-4, available at: www.scopus.com

Lytras, M.D., Damiani, E. and Mathkour, H. (2016), "Virtual reality in learning, collaboration and behaviour: content, systems, strategies, context designs", Behaviour and Information Technology, Vol. 35 No. 11, pp. 877-878, doi: 10.1080/0144929X.2016.1235815.

Lytras, M.D., Raghavan, V. and Damiani, E. (2017), "Big data and data analytics research: from metaphors to value space for collective wisdom in human decision making and smart machines", International Journal on Semantic Web and Information Systems, Vol. 13 No. 1, pp. 1-10, doi: 10.4018/IJSWIS.2017010101.

Visvizi, A., Mazzucelli, C.G. and Lytras, M. (2017), "Irregular migratory flows: towards an ICT-enabled integrated framework for resilient urban systems", Journal of Science and Technology Policy Management, Vol. 8 No. 2, pp. 227-242, available at: https://doi.org/10.1108/JSTPM-05-2017-0020.

Wu, S.M., Chen, T., Wu, Y.J. and Lytras, M. (2018), "Smart cities in Taiwan: a perspective on big data applications”, Sustainability (Switzerland), Vol. 10 No. 1, doi: 10.3390/su10010106. 